\title{
Para além do relatório: experiências de escrita no estágio em ensino de química
}

\author{
In addition to the report: writing experiences in the \\ chemistry teaching internship \\ Más allá del informe: experiencias de escritura en la \\ etapa de enseñanza de química
}

FRANKLIN KAIC DUTRA-PEREIRA

https://orcid.org/0000-0003-4486-6124

Universidade Federal do Recôncavo da Bahia

Faculdade de Química

Centro de Formação De Professores

Amargosa, BA, Brasil

MICHELE MARCELO SILVA BORTOLAI

https://orcid.org/0000-0002-9837-7062

Universidade Federal do Recôncavo da Bahia

Faculdade de Química

Centro de Formação De Professores

Amargosa, BA, Brasil

RAFAELA DOS SANTOS LIMA

https://orcid.org/0000-0002-7573-9884

Universidade Federal do Recôncavo da Bahia

Faculdade de Educação

Programa Pós-Graduação em Ensino, Filosofia e História das Ciências

Salvador, BA, Brasil

Resumo: Discutimos neste artigo a importância da escrita e da elaboração de documentos pedagógicos nos Estágios Supervisionados em Ensino de Química de uma universidade do interior da Paraíba. Utilizamos como referencial teórico os escritos de Schon (2000) e Souza (2013) para formação de professores numa perspectiva crítico-reflexiva. Nos apoiamos em Queiroz (2001), Silva (2013), Cabral e Flôr (2016) e Pimenta e Lima (2017), para as inferências sobre o Estágio Supervisionado. A metodologia parte de concepções de abordagem qualitativa do tipo descritiva. Utilizamos, também, a diversidade dos documentos pedagógicos, que possibilitaram a compreensão dos saberes da experiência, a correlação entre a história de vida e ser professor(a) de Química. Assim, concluímos que o ato de escrever e registrar proporcionou o reconhecimento de nuances da formação de professores de Química, assim como permitiu entender a necessidade de uma formação que desenvolva as habilidades de escrita como um processo de construção permanente.

Palavras-chave: Ensino de Química; Formação de professores; Estágio Supervisionado; Prática de Registros; Documentos Pedagógicos. 


\begin{abstract}
In this article, we discuss the importance of writing and preparing pedagogical documents in Supervised Internships in Teaching Chemistry at a university in the interior of Paraiba. We used as a theoretical reference the writings of Schon (2000) and Soura (2013) for teacher training in a critical-reflexive perspective. We rely on Queiroz. (2001), Silva (2013), Cabral and Flôr (2016), and Pimenta e Lima (2017) for the inferences about the Supervised Internship. The methodology starts from conceptions of a qualitative approach of descriptive type. We used the diversity of pedagogical documents, which made it possible to understand the knowledge of the experience, the correlation between life history and being a chemistry teacher. Thus, we conclude that the act of writing and registering provided the recognition of nuances in the formation of Chemistry teachers, as well as understanding the need for training that develops writing skills as a process of permanent construction.
\end{abstract}

Keywords: Chemistry Teaching; Teacher Training; Supervised Internship; Records Practice; Pedagogical Documents.

Resumen: Discutimos en este artículo la importancia de la redacción y elaboración de documentos pedagógicos en Pasantías Supervisadas en Docencia Química en una universidad del interior de Paraíba. Utilizamos como referencia teórica los escritos de Schon (2000) y Souza (2013) para la formación del profesorado en una perspectiva crítico-reflexiva. Nos apoyamos en Queiroz. (2001), Silva (2013), Cabral y Flôr (2016) y Pimenta e Lima (2017), para las inferencias sobre la Pasantía Supervisada. La metodologia parte de concepciones de abordaje cualitativo de tipo descriptivo. También utilizamos la diversidad de documentos pedagógicos, que permitieron comprender el conocimiento de la experiencia, la correlación entre historia de vida y ser profesor de química. Así, concluimos que el acto de escribir y registrar proporcionó el reconocimiento de matices en la formación de los docentes de Quimica, así como la comprensión de la necesidad de una formación que desarrolle las habilidades de escritura como un proceso de construcción permanente.

Palabras clave: Enseñanza de la Química; Formación de profesores; Pasantía supervisada; Práctica de registros; Documentos pedagógicos.

\title{
INICIANDO UMA CONVERSA
}

A graduação no Ensino Superior é o momento oportuno para formação de diferentes profissionais. Apesar de todas as polêmicas e sucateamento, as universidades brasileiras têm lançado estratégias diversificadas para continuarem equânimes e democráticas, na tentativa de formar pessoas com competências e habilidades plausíveis para exercerem sua profissão. É importante este enunciado em forma de protesto no texto acadêmico, pois estamos vivenciando retrocessos nas Instituições de Ensino Superior (IES), pós golpe de 2016, momento em que a Educação está sendo vista como inimiga principal, sobretudo as universidades federais.

É notório que apesar de todos os retrocessos, incorporados a uma perspectiva política de formação neoliberal com traços neofascistas que, em contrapartida, temos resistido e tentado - ao menos nas disciplinas de cunho 
pedagógico - formar professores críticos, reflexivos e contrários ao que está sendo imposto nas próprias IES brasileiras. Por isso, pensamos aqui, na formação crítica do docente em Química, com posicionamento questionador para pensar em mudanças da realidade e não apenas com percepções tecnicistas e reducionistas de ensino-aprendizagem, como abordado nos cursos de formação de professores de Ciências, entre os anos 60 e início dos anos 80 (VIANNA, 2004).

Neste contexto de formação docente na concepção da racionalidade técnica, o papel do professor de Ciências é reduzido à simples execução técnica de tarefas programadas e controladas por manuais didáticos, sendo preparado para memorizar as informações científicas que seriam transmitidas aos estudantes, por meio de procedimentos didáticos sugeridos por profissionais da Educação. Tal formação docente, originada sob o pressuposto da disciplinaridade científica, possibilitou a criação de currículos tradicionais, lineares e fragmentados, bem como a especialização de saberes, de materiais didáticos e da formação docente (VIANNA, 2004), sem a contemplação de adaptação dos processos educacionais às reais condições de aprendizagem dos educandos.

Contudo, de acordo com Schon (2000) e Souza (2013), a formação de professores numa perspectiva crítico-reflexiva possibilita a transformação das práticas pedagógicas, pela ressignificação de valores e sentidos ideológicos implícitos no processo de ensino-aprendizagem e na instituição escolar. No geral, esse movimento exige uma ação transformadora, dirigida ao combate da irracionalidade e da injustiça ainda presentes em instituições educativas.

Dito isto, entendemos que os cursos de formação docente devem buscar uma estreita relação entre o ensino e a pesquisa, isto é, entre a teoria e a prática, buscando sempre a transformação social, a superação das desigualdades e a consciência de seus limites e possibilidades de avanços. Poderemos, assim, diminuir a responsabilização dos professores pelos problemas educacionais, que estão diretamente relacionados à ideologia neocapitalista dominante na sociedade atual - que defende o princípio da competição mercadológica como reguladora da sociedade (SOUZA, 2013).

Ao pensarmos na formação docente é perceptível que alguns critérios têm levado as universidades, junto ao corpo docente/discente, a incorporar práticas que conduzam a uma clareza dos conhecimentos que estes profissionais precisam adquirir durante sua trajetória acadêmica. Assim, entra neste patamar de discussão, a importância da prática de registrar as atividades realizadas nos Estágios Supervisionados em Ensino de Química (ESEQ), por meio da escrita.

O estágio supervisionado tem adquirido um papel importante para a formação de professores, por ser uma possibilidade de retroalimentação dos projetos pedagógicos e um espaço para que se conheça a realidade e o cotidiano 
escolar, em que os(as) professores(as) se relacionam e se formam, ao mesmo tempo em que aprendem e escrevem sobre si e sobre o outro, na perspectiva de criação de uma identidade docente.

No Parecer do Conselho Nacional de Educação CNE/CP 28/2001 (BRASIL, 2001), o estágio supervisionado é definido como a relação pedagógica entre o aluno(a) e alguém que já é um profissional reconhecido, em um ambiente institucional de trabalho, onde se permanece por um certo período de tempo para aprender a prática e depois exercer uma profissão ou ofício.

O Estágio Supervisionado em Ensino deve ser realizado levando-se em consideração fundamentos teóricos, bem como as práticas docentes realizadas por meio da vivência das atividades escolares, considerando-se a resolução CNE/ CEB n ${ }^{\circ} 4 / 2010$ (BRASIL, 2010) e todos os seus desdobramentos, principalmente a resolução CNE/CP nº. 2/2015 (BRASIL, 2015).

Pimenta e Lima (2017) alertam que o Estágio Curricular Supervisionado (ECS), nos cursos de licenciaturas, não deve ser encarado enquanto mero componente curricular, mas sim como um importante recurso para a formação inicial docente. O ECS é constituído por reflexões acerca dos processos de ensino e aprendizagem.

Envolve a coleta de informações, com objetivo de conhecimento da realidade acerca do cotidiano da escola, da sala de aula e dos alunos, objetivando a elaboração de um diagnóstico da situação do campo de estágio.

Para as autoras, essa conduta investigativa busca a construção de saberes científico-pedagógicos, por meio do desenvolvimento da pesquisa, um elemento importante para a formação do licenciando, uma vez que estimula a reflexão e a intervenção no cotidiano escolar, na vida dos professores e na vida dos alunos. Assim, o estágio exerce dupla função, a reflexão e a pesquisa sobre a prática pedagógica.

Silva (2013) também discute a questão do ECS, afirmando dissenso dos formadores quanto às estratégias adotadas no componente curricular e a melhor forma dos alunos apresentarem as observações e reflexões sobre as atividades praticadas na escola. Sendo assim, geralmente, optam por uma única e já consolidada possibilidade de documentação pedagógica, o Relatório de Estágio, que é elaborado a partir das experiências vividas, em um contexto sócio-histórico, constituído como significativo para a aprendizagem do aluno-estagiário.

Infelizmente, o que temos observado em nossas aulas, é que o Relatório de Estágio tem sido reduzido a um documento que os licenciandos elaboram, em cumprimento ao que lhes é exigido no processo avaliativo dos cursos ou pelo 
regulamento dos ECS. Essa compreensão empobrece a sua função primeira, que seria apresentar reflexões críticas da práxis docente e/ou a ressignificação da identidade do profissional em formação.

A materialização do relatório de estágio, no formato de documento pedagógico seria a função secundária, ou seja, funcionar como suporte para o registro do processo reflexivo e investigativo. A ênfase, portanto, deveria estar no processo e não no produto, como tem sido recorrente.

Isto posto, consolida-se o ideário do relatório técnico-científico vir de uma postura positivista e da necessidade de plotar e registrar dados em gráficos. Fato recorrente nas disciplinas de cunho experimental dos cursos de Licenciatura em Química, que têm utilizado essa forma de registro, ocasionando que os estudantes, quando em período de Estágio Supervisionado em Ensino de Química (ESEQ), queiram utilizá-lo da mesma forma.

Sendo assim, foi e é importante usarmos de outros gêneros textuais para que possamos escrever as nossas ações, emoções e até mesmo frustrações experienciadas nos ESEQ. Porém, a diversificação dos meios e práticas de registros geralmente ocorre no final dos cursos, dificultando o processo reflexivo, pois escrever é um processo criativo, principalmente, quando estamos dialogando com aportes teórico-metodológicos da ação docente.

Destaca-se que nos cursos de formação de professores(as) de Química são recorrentes as dificuldades de comunicação, por meio de registros escritos pelos licenciandos (QUEIROZ, 2001). De um lado há uma valorização de conhecimentos cognitivos quantitativos no/do curso, acarretando uma limitação nas habilidades qualitativas, sobretudo no ato de escrever, que corrobora e reflete - negativamente - nas disciplinas pedagógicas. Cabral e Flôr (2016) têm criticado essa situação, pois há uma concepção de que o trabalho com a escrita no curso de formação docente em Química está relacionado somente a disciplinas de Língua Portuguesa.

Assim, diferentes práticas de registros da documentação pedagógica se iniciam no universo acadêmico das licenciaturas, a partir do uso de diversificadas formas de registrar a prática e refletir sobre os processos vividos no ambiente escolar e universitário, com a finalidade de que se possa pautar um planejamento flexível e uma pedagogia da escuta.

Neste artigo, a documentação pedagógica discutida será retratada como aspecto essencial da ação investigativa do docente, como instrumento de formação profissional e de registros das práticas na formação inicial, realizadas durantes os ESEQ. Dentre elas, destacamos o Memorial Formativo, o Diário de Campo e a Carta como estratégias de registro da prática e/ou da prática de registros. 
Nesse sentido, buscamos defender, nesta discussão, a pluralidade da documentação pedagógica, para que possamos registrar de forma escrita a reflexão na/da/sobre a prática de ensino desenvolvida no decorrer dos ESEQ, ou até mesmo durante a trajetória acadêmica. Por esse motivo, a escrita deste texto tem como objetivo discutir diferentes produções de documentos pedagógicos, utilizados e orientados para registrar a prática nos ESEQ, além de refletir sobre a contribuição da prática de registros no/do/sobre o ESEQ, a fim de uma formação crítica-reflexiva pautada na ressignificação social.

\section{DOS MODOS DE FAZER. O QUÊ? COMO?}

Considerando os objetivos investigativos apresentados para este trabalho, classificamos a presente pesquisa como de abordagem qualitativa, uma vez que produzimos dados predominantemente descritivos. Como consequência, destacamos o significado que os participantes deram aos fatos e à sua própria vida, interpretando os dados de maneira indutiva (LÜDKE; ANDRÉ, 1986).

Consequentemente, assumimos os princípios da tipologia descritiva, a qual tem a finalidade de expor características, fatos e fenômenos de determinada realidade (GIL, 2002; TRIVIÑ̃S, 1987). Então, refletimos sobre como tem se dado a construção de diferentes registros e suas múltiplas características enquanto documentação pedagógica, a fim de evidenciar e incentivar outras práticas de registros nos ESEQ.

A documentação pedagógica analisada foi obtida de diferentes propostas de criação/elaboração de textos escritos pelos alunos na disciplina de ESEQ, durante o segundo semestre de 2017 até o final do primeiro semestre de 2019, em uma Instituição Federal de Ensino Superior (IFES) do estado da Paraíba.

Assumimos, para análise. os seguintes documentos pedagógicos: o Memorial Formativo, o Diário de Campo e a Carta, escrita pelos licenciandos e endereçada ao Diretor da unidade escolar, enquanto objetos de estudo, uma vez que estão presentes em vários gêneros e suportes textuais, apresentando histórias vividas ou fictícias. Esses documentos fazem parte do repertório cultural de todas as faixas etárias e localidades, compondo a história da humanidade, uma vez que nunca existiu, em nenhum lugar e em tempo algum, ausência de registros durantes os ESEQ. Os documentos pedagógicos configuram-se como uma das tantas possibilidades de materialização narrativa das práticas pedagógicas no Ensino de Química.

É importante frisar que as orientações e templates para os registros foram previamente planejados com os(as) licenciandos(as), para que no final chegássemos ao consenso de qual documento pedagógico iríamos utilizar. Tivemos um total 
de 48 documentos produzidos e disponibilizados para a pesquisa. Neste artigo, optamos por três documentos pedagógicos como amostra de cada turma da disciplina de ESEQ, para que dispuséssemos de um espectro representativo para a análise.

Assim, o corpus de análise se constituiu com 9 documentos pedagógicos, que foram lidos na íntegra e separados categoricamente por gêneros. Os escritos dos licenciandos(as) sobre o ESEQ são modelos explicativos e representativos para que outros cursos de licenciaturas possam utilizar os gêneros nas suas disciplinas. Além disso, tais escritos expressam as diferentes visões do ESEQ e das experiências exequíveis durante o processo formativo. Por isso, visando explorar tais argumentos, recorremos à análise de conteúdo como estratégia metodológica de categorização e análise dos documentos pedagógicos, uma vez que funciona "[...] como um conjunto de técnicas de análise das comunicações visando obter [...] indicadores (quantitativos ou não) que permitam a inferência de conhecimentos relativos às condições de produção/recepção [...] destas mensagens." (BARDIN 2011, p. 42),

A escolha da análise de conteúdo se justifica pela riqueza da técnica, por ser diversificada e utilizada em diversas pesquisas, sobretudo na Educação Química. Deve-se, também, por acreditarmos na possibilidade da sua utilização na análise de diversos gêneros textuais e expressões que surgem nos documentos pedagógicos. Conforme afirma Bardin (2011, p. 11), a análise de conteúdo “[...] oscila entre os dois polos do rigor da objetividade e da fecundidade da subjetividade. Absolve e cauciona o investigador por esta atração pelo escondido, o latente, o não-aparente, o potencial de inédito (do não-dito), retido por qualquer mensagem."

A fim de absorvermos o escondido, o latente, o não-aparente, seguimos algumas recomendações dadas pela autora ao nos debruçarmos na análise dos documentos pedagógicos, visando definir os eixos e as categorias de nossa análise.

\section{O memorial formativo: frustrações, desventuras e aventuras de uma discente}

Passeggi (2008a) denomina os memoriais autobiográficos como um conjunto de escritos para responder a uma demanda institucional. Sendo assim, enquanto gênero textual e instrumento avaliativo levam os sujeitos sociais a refletirem sobre suas trajetórias de vida e práticas desenvolvidas - visão da qual compartilhamos. 
O memorial tem importante utilidade na vida acadêmica, tanto em termos de uso institucional, como em termos de retomada e avaliação da trajetória pessoal no âmbito acadêmico-profissional. [...] O memorial é mais relevante quando se trata de se ter uma percepção mais qualitativa do significado dessa vida, não só por terceiros, responsáveis por alguma avaliação escolar, mas sobretudo pelo próprio autor. (SEVERINO, 2007, p. 244).

O memorial pode ser visto como um instrumento rico de fatos e acontecimentos, constituído como material autobiográfico, histórico e reflexivo. Pode ser classificado, segundo Passeggi (2008b), em memoriais acadêmicos (aqueles que são escritos por professores e/ou outros profissionais, objetivando uma aprovação em concurso público ou uma ascensão na carreira) e memoriais de formação (aqueles elaborados por pessoas que se encontram em formação profissional, visando a uma certificação).

Adotando, então, a categorização das tipologias de memoriais, realizada por Passeggi (2008b), trabalhamos em nossa pesquisa com memoriais de formação como fonte de obtenção de dados. Na Figura 1, tem-se o sumário do Memorial Formativo que fora apresentado aos estudantes, como ponto de partida, durante os ESEQ, partindo dos pressupostos existentes nas relações entre os saberes da experiência, os saberes curriculares e os saberes pedagógicos, ancorados na literatura de Tardif (2014). 


\section{Figura 1 - Sumário do Memorial Formativo utilizado nas turmas de ESEQ}

\begin{tabular}{|c|}
\hline SUMÁRIO \\
\hline 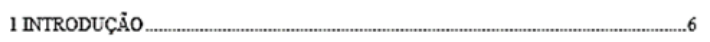 \\
\hline 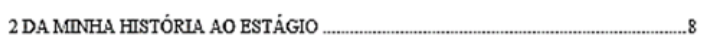 \\
\hline 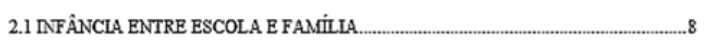 \\
\hline 3 INGRESSO E ESCOLHA DO CURSO......... \\
\hline $\begin{array}{l}4 \text { O FAZER E AS DIFICULDADES ENCONTRADAS DONO CURSO DE QUIMICA - } \\
\text { LICENCLATURA }\end{array}$ \\
\hline $\begin{array}{l}5 \text { INTERFACE ENTRE O PROGRAMA RESIDĖNCLA PEDAGÓGLA E O ESTÁGIO } \\
\text { SUPERVISIONADO NO ENSINO DE QULIMICA }\end{array}$ \\
\hline 6 OS ESTÁGIOS SUPERVISIONADOS EM ENSINO DE QUUMICA E MINHAS \\
\hline PRÁTICAS PEDAGÓGICAS \\
\hline 6.1 A CARACTERIZAÇÃO DA ESCOLA 24 \\
\hline 6.2 A OBSERVAÇ̃̃o \\
\hline 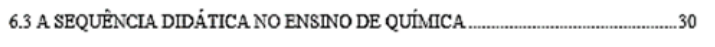 \\
\hline 6.4 DESENVOL VIMENTO DA SEQUÊNCLA DIDÁTICA - ANÁLISE CRITICA ..............38 \\
\hline 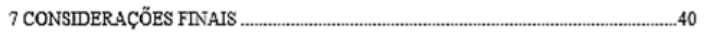 \\
\hline REFERÊNCIAS .......................... \\
\hline ANEXOS \\
\hline APÊNDICES .... \\
\hline
\end{tabular}

Fonte: Os autores (2020)

Durante a escrita dos memoriais observamos que vários estudantes relataram a necessidade dos cursos de licenciatura enfatizarem a importância de se fazerem presentes as histórias de vida de cada sujeito envolvido na realização dos ESEQ. Abaixo, apresento um excerto de um dos Memoriais (2018), sobre o ato de escrever um/o Memorial no contexto do ESEQ.

Entendendo o Estágio Supervisionado II como um momento voltado à reflexão, o presente memorial apresenta todos os pensamentos, frustrações, desventuras e aventuras de uma discente do curso de Química que acabara de se inserir como professora de uma escola estadual da cidade do Estado da Paraíba. Busca-se ao longo das páginas que se seguem apresentar ao leitor como a identidade docente vai sendo progressivamente (re)construída, (re)avaliada e (re)pensada.

Avaliando as atividades desenvolvidas no Estágio Supervisionado II, bem como refletindo sobre o meu desenvolvimento enquanto docente iniciante, posso afirmar que esta fase da minha formação foi bastante enriquecedora, rodeada de descobertas e reflexões. Sem dúvidas saio desta disciplina com pensamentos e olhares mais atentos à realidade escolar. Me vejo implicada na vida dos meus alunos. 
Durante a disciplina reafirmei meu lugar como docente e mulher, pude me ver intrincada em uma luta de muitas. Fui e sou resistência e posso garantir que meus esforços e minha voz serão erguidos em busca da igualdade de gênero. Não basta rechaçar o machismo, é necessário lutar contra ele diariamente.

Finalizo minhas palavras enfatizando a alegria que sinto em chegar ao final desta disciplina tendo cumprido adequadamente tudo que fora proposto. Acredito que todas as atividades desenvolvidas afetaram diretamente o meu reconhecimento enquanto professora de química, bem como me possibilitaram ver a dimensão política, social e cultural do meu trabalho.

O sumário e o excerto dão noção sobre a necessidade de correlacionar a formação inicial dos professores de Química com as histórias de vida de cada licenciando(a). O Memorial Formativo, como podemos ver, entrelaça, de forma escrita o vivido e o percebido na sua trajetória escolar e no ESEQ. Essa aproximação entre o vivido e o percebido é necessária para que entendamos como os estudantes se constituem enquanto professores(as) de Química. Ainda assim, é importante perceber que cada palavra dita pelos(as) estudantes expressa o desejo pela mudança, pela resistência e pela equidade de possibilidades entre as pessoas.

Por esse motivo, o Memorial Formativo, ao revelar diferentes formas de falar de si mesmo, utiliza recursos diversos do conteúdo das narrativas de formação e se vincula ao cotidiano na busca de um saber fazer constante (SOUZA, 2006). Assim, o saber fazer se inscreve como uma sabedoria experiencial do percurso de cada sujeito e é marcado por aprendizagens construídas ao longo da vida.

Com efeito, as relações entre a memória, as experiências do vivido e do percebido, do acompanhamento e do cuidado, marcam singularidades no trabalho de formação docente, mediante as escritas como dispositivos autoformadores. Isto é, como enfatiza Souza (2006), essas reflexões concebidas durante a escrita do Memorial Formativo nos levam a pensar sobre os diferentes modos de como vivemos a infância e, de modo transferencial, como nós, professores, poderemos desenvolver formas de acompanhamento, cuidado e atenção durante a formação dos nossos alunos.

\section{Diário de campo: as percepções dos professores de química}

As memórias, quando escritas, passam a ter sentido e podemos enxergar e sistematizar o pensamento. Daí a defesa da escrita através de diversos gêneros textuais nos cursos de Licenciatura em Química.

Quanto ao Diário de Campo, Zabalza (2004) esclarece que o ato de escrever sobre as práticas que ocorrem, no contexto escolarizado ou não, dão mais clareza sobre os fatos vividos e historicizados, possibilitando nosso retorno 
às narrativas para analisá-las ou até mesmo revisá-las, por isso sua ampla utilização em cursos de licenciatura serem múltiplas.

O Diário de Campo, quando trabalhado nos ESEQ, oferece diferentes pontos sincrônicos e diacrônicos (ZABALZA, 2004), no sentido de compreendermos e vivenciarmos, a partir da escrita, o que ocorreu no cotidiano escolar, quais foram as reflexões $\operatorname{dos}(\mathrm{as})$ licenciandos(as) e quais proposições registraram, na tentativa da mudança da realidade, tão defendido no curso em questão. Além disso, é possível observar também, a evolução em que os registros das práticas acontecem. Dizemos isso no sentido em que os licenciandos começam sua escrita de forma mais introdutória e, por fim, aperfeiçoam os próprios registros, baseados nas experiências vivenciadas. A exemplo, apresentamos na Figura 2 o diário de campo de um dos estudantes.

\section{Figura 2 - Narrativas de diário de campo 1}

\begin{tabular}{|c|c|c|c|}
\hline Hora & Descrição & $\begin{array}{c}\text { Interpretação (questões problematizadoras, } \\
\text { inferêndias e conjecturas) }\end{array}$ & $\begin{array}{c}\text { Fundamentação do estagiário } \\
\text { (argumentos baseado com a literatura) }\end{array}$ \\
\hline $\begin{array}{c}08: 20 \\
\text { a } \\
09: 00\end{array}$ & 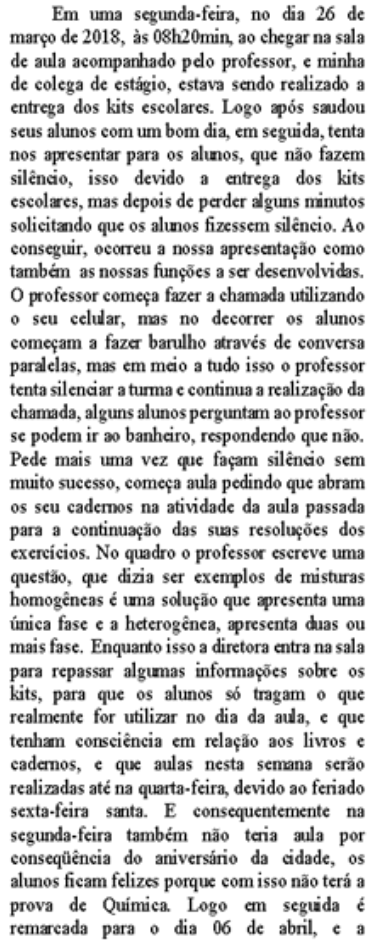 & $\begin{array}{l}\text { Contudo que foi possivel observar no } \\
\text { decorrer das duas aulas, um dos principais } \\
\text { problemas na sala de aula, é por que o professor } \\
\text { não consegue controlar sua turma, devido ser } \\
\text { uma grande quantidade de alunos, para uma sala } \\
\text { tão pequena, e sendo assim os alunos fieam, mas } \\
\text { próximos, e é assim que surgir as conversas } \\
\text { paralelas, sem que ocorra o total silêncio durante } \\
\text { a aula. }\end{array}$ & $\begin{array}{l}\text { O silêncio, e as conversas são dois } \\
\text { elementos muitos importantes dentro da sala } \\
\text { de aula que podem trazer beneficios ou não, } \\
\text { pois depende do contexto, e da situação, que } \\
\text { está acontecendo. Mas alguns professores } \\
\text { eonsideram que o silêneio absoluto, em sala } \\
\text { de aula assegura uma melhor aprendizagem, } \\
\text { do mesmo modo. As conversas soltas e } \\
\text { desvineuladas podem retrocede a } \\
\text { aprendizagem. } \\
\text { De acordo com Freire (2006,) Se consegui a } \\
\text { garantia de um espaço, para o silêncio, e } \\
\text { eonversa em sala de aula, conversa } \\
\text { entendida como demento importante na } \\
\text { construção de conhecimento e forma de } \\
\text { expressão e o silêncio como concentração e } \\
\text { respeito ao colega que está aprendendo. } \\
\text { Segundo Gemino Sacristan (2002,) } \\
\text { também defende a eoneepção de sujeito } \\
\text { comunicativo, e de interação e de } \\
\text { movimento, para ele, isso faz parte da } \\
\text { aprendizagem. } \\
\text { Também existe o silêncio estabelecido } \\
\text { eomo uma regra, na sala de aula O silêncio } \\
\text { imposto pelos professores como necessánio, } \\
\text { julgam que a aula deve transeorrer de forma } \\
\text { silenciosa, pois a liberdade de interação } \\
\text { dentro da sala de aula, assim podendo } \\
\text { desfavorecer a ordem, e o bom andamento } \\
\text { das aprendizagens. Portanto Trata-se de um } \\
\text { silêncio imperativo. (BARBoSA e BORBA, } \\
2011 \text { ). }\end{array}$ \\
\hline
\end{tabular}

Fonte: Os autores (2020) 
O diário de campo é um dos meios de registro das observações durante o ESEQ. É possível perceber que a estrutura e o que se solicita no diário de campo servem para organizar o pensamento dos licenciandos. Nele, os estudantes descrevem suas concepções, entendimentos e percepções do que conseguem observar no contexto em que se realiza o ESEQ. A partir dessas observações escritas tem-se as problematizações do que fora observado e sua posterior contextualização a partir da literatura específica de cada área do ensino.

A utilização dessa ferramenta como forma de registro alternativa é necessária para que os estudantes tenham consciência de que suas observações durante a prática do ESEQ não estão distantes da teoria, contrariando um costume ainda persistente nos ESEQs, de uma visão de distanciamento entre a teoria e a prática. Há muito temos discutido e defendido que a teoria ilumina a prática e a ressignifica. Essas deturpações da importância dos ESEQ se enveredam pelas (re) significações da própria prática pedagógica até as revisões constantes da função social da docência em sua interface entre a teoria e a prática.

Partindo dessa perspectiva, podemos afirmar que os saberes da experiência são desenvolvidos no trabalho cotidiano e no conhecimento de seu meio, de tal forma que sustentem a sua origem na própria prática e no confronto com as condições de realização de sua profissão.

O Diário de Campo apresentado na Figura 2, traz narrativas escritas realizadas pelo(a) estudante. Essas narrativas contribuem para a constituição e revelação dos saberes da experiência docente, tornando perceptíveis evidências do exercício do poder do professor supervisor ${ }^{1}$ do ESEQ na relação professoraluno. Também o discurso do silêncio durante as aulas, sem respeitar, por vezes, o espaço dos estudantes ao receberem seus kits escolares, pode ser apreciado nas narrativas registradas pelo licenciando no Diário de Campo.

De acordo com Tardif (2014), os saberes da experiência se configuram para o(a) estagiário(a) a partir de três objetivos: as relações e interações que os professores estabelecem e desenvolvem no campo de sua prática; as diversas obrigações e normas às quais seu trabalho deve submeter-se e, por fim, a instituição enquanto meio organizado e composto de funções diversificadas. Esses são objetivos que constituem a prática docente e que só se revelam através dela, ou seja, vão além das condições de trabalho da profissão, conforme podemos constatar no Diário de Campo analisado.

$\mathrm{Na}$ narrativa escrita no próximo Diário de Campo (Figura 3), podemos observar o que defendemos quanto à evolução da (re)escrita dos Diários de Campo. Notamos que a discussão central das atividades realizadas em sala de aula pelo

1 Nos referimos ao professor(a) da escola que recebem os(as) estagiários(as) como "professor supervisor".

194 - Rev. Bras. Polít. Adm. Educ. - v. 37, n. 1, p. 183 - 206, jan./abr. 2021 
Professor Supervisor do ESEQ, ainda perpetuada durante no curso de licenciatura em Química, diz respeito às listas de exercícios, como possibilidade de "treinar" as habilidades e competências dos alunos nas questões apresentadas, durante o processo de ensino-aprendizagem. A observação realizada pelo licenciando nos mostra o reducionismo conferido pelo Professor Supervisor do ESEQ quanto à utilização de um recurso didático no processo de ensino educacional, assim como, também a desconsideração aos conhecimentos prévios dos alunos, o que nos leva a considerar a racionalidade técnica, ainda predominante nas escolas de Educação Básica brasileiras.

\section{Figura 3 - Narrativas do diário de campo}

\begin{tabular}{|c|c|c|c|c|}
\hline $\begin{array}{l}\text { DATA } \\
25 / 04\end{array}$ & $\begin{array}{c}\text { HORA } \\
13: 00 \\
\text { às } \\
14: 20\end{array}$ & $\begin{array}{l}\text { DESCRIÇÃo } \\
\text { (Aspectos que merecem destaque) } \\
\text { Era dia de receber as provas e dar } \\
\text { inicio a outro conteúdo. Todos } \\
\text { esperavam ansiosos quando o } \\
\text { professor entrou na sala e deu boa } \\
\text { tarde se direcionando ao birô. Como } \\
\text { de costume, o professor pegou o } \\
\text { celular e iniciou a chamada. Os } \\
\text { alunos pareciam está um pouco } \\
\text { "agitados" e foi preciso o professor } \\
\text { pedir silêncio várias vezes até que } \\
\text { parassem de fazer barulho. Após } \\
\text { terminar a chamada o professor } \\
\text { chama um por um para receber a } \\
\text { prova e mostrar o caderno para } \\
\text { receber o famoso visto. O visto no } \\
\text { caderno valia um ponto, portanto, } \\
\text { quem tirasse sete na prova e tivesse } \\
\text { um visto, ficaria com oito pontos na } \\
\text { nota. Dado os resultados o professor } \\
\text { parabeniza a turma por terem } \\
\text { alcançado um resultado razoável e, } \\
\text { fala para os que não conseguiram } \\
\text { êxito na prova, que faltou um pouco } \\
\text { de esforço. Em seguida, deu-se início } \\
\text { ao novo conteúdo: concentração em } \\
\text { quantidade de matéria. Durante a } \\
\text { explicação do conteúdo alguns alunos } \\
\text { interrompiam para dizer que não } \\
\text { estavam entendendo. o professor } \\
\text { retornava e explicava até sanar as } \\
\text { dúvidas. Após terminar as } \\
\text { explicaçōes, o professor fala: "vou } \\
\text { entregar um exercício sobre o } \\
\text { conteúdo para vocês exercitarem um } \\
\text { pouco. Se vocês estiverem craques a } \\
\text { prova será de hoje a oito dias, caso } \\
\text { não estejam, será de hoje a quinze". } \\
\text { Uma aluna falou; "não, professor. } \\
\text { Semana que vem não, pelo amor de } \\
\text { Deus". Eu, brincando, falei: "o }\end{array}$ & $\begin{array}{l}\text { PROBLEMATIZAÇÃO } \\
\text { (Questöes/hipótesesinferências sobre } \\
\text { os destaques) } \\
\text { Minha questão de destaque é a presença } \\
\text { frequente de listas de exercícios nas aulas, } \\
\text { que na visão do professor servem para } \\
\text { "exercitar" o conhecimento dos alunos. }\end{array}$ & $\begin{array}{l}\text { PROPOSIÇÃO } \\
\text { (Encaminhamentos/propostas para } \\
\text { cada situação destacada) } \\
\text { Minha proposta seria fazer uma aula } \\
\text { diferente da habitual, onde o professor, } \\
\text { juntamente com os alunos, } \\
\text { desenvolvesse algum experimento que } \\
\text { envolvesse as ideias de concentração, } \\
\text { massa e volume. Tendo em vista que os } \\
\text { exercicios da lista săo repetitivos e } \\
\text { utilizam do mesmo método para } \\
\text { responder cada questajo. Resumindo, } \\
\text { desperdiça-se muito tempo apenas } \\
\text { focando em uma lista de exercícios, } \\
\text { quando se poderia trabalhar o conteúdo } \\
\text { de outras formas. }\end{array}$ \\
\hline
\end{tabular}

Fonte: Os autores (2020)

Conforme salientamos, as escritas das observações, acompanhada das problematizações remetem ao eixo central da formação docente, que preocupa-se com a transformação da realidade educacional. No registro de suas observações, o licenciando frisou a familiaridade desta prática de listagem de exercícios nas escolas-campo do ESEQ e a prática ainda presente nos cursos de Licenciatura 
em Química. O licenciando destacou que é premente a mudança dessa tradição tecnicista por outras estratégias mais inclusivas de consideração aos conhecimentos dos educandos.

Os Diários de Campo são importantes no processo de registro da prática docente, pois permite aos estudantes um status de observadores críticos das ações da escola. Essa prática reflexiva também contribui para que o licenciando possa se avaliar, enquanto futuro professor de Química.

Esta é uma prática que precisa ser valorizada nos ESEQ, pois a partir dela é possível uma conscientização dos padrões encontrados nas diferentes escolas em que atuaram os estagiários desta pesquisa. Assim, as informações contidas nos Diários de Campo (Figura 2 e 3) nos dão noção da dimensão da prática docente. Conforme afirma Zabalza (2004), os Diários de Campo servem para os licenciandos se conscientizarem da importância da experiência vivida na escolacampo como recurso autoformativo dos profissionais da educação.

Os diários contribuem de maneira notável para o estabelecimento de um “[...] círculo de melhoria capaz de nos introduzir em uma dinâmica de revisão e enriquecimento de nossa atividade como professores" (ZABALZA, 2004, p. 11). Portanto, nesta turma de ESEQ, as observações dos licenciandos foram realizadas de acordo com os acontecimentos presentes nas aulas observadas. Essas observações foram fundamentais na elaboração desse documento pedagógico.

Através desse documento foi possível entender alguns significados de se escrever o Diário de Campo em interlocução com o observado e as concepções dos saberes da experiência. Assim, julgamos que os registros nos Diários de Campo apresentados pelos licenciandos contribuem para dar outros sentidos e significados às experiências vividas e percebidas no contexto escolar.

\section{As cartas de jovens professores de química}

Esta categoria faz uma paráfrase com os livros Cartas a um jovem professor, de Philippe Meirieu (2006) e Cartas a um jovem cientista, de Gleiser (2007). O primeiro livro leva o

[...] jovem professor a prover-se de um 'kit de sobrevivência' para fazer face aos problemas de disciplina, construindo para si mesmo algumas convicções sobre os perigos da mercantilização da escola e recolhendo, aqui e ali, as informações necessárias para a gestão de sua carreira. (CAMARA BASTOS, 2006, p. 646). 
Quanto ao segundo livro:

[...] seu objetivo é narrar suas próprias experiências na juventude, [...] que tiveram relação com sua carreira científica. Nesse aspecto, o relato [...] favorece a identificação dos potenciais futuros cientistas - a quem as cartas são efetivamente direcionadas" (MOURA, 2014, p. 29).

Esses livros são necessários para conhecer as diferentes visões preestabelecidas na formação docente, pelo fato de que que cada estudante traz consigo concepções de ser/fazer professor(a) de Química. Meirieu (2006) traz em seus escritos um olhar a partir da concepção mercantilista e da sobrevivência do docente na escola. Enquanto Moura (2014) apresenta as visões de Ciência(s) de jovens que querem ser professores, as quais poderão necessitar quando se depararem com a pesquisa e construção do conhecimento científico-escolar.

Trazemos esses autores pela necessidade de contemplar e respaldar que as cartas que seguirão em análise nesta seção são necessárias para a interpretação das ações dos(as) licenciandos(as) durante o ESEQ e, além disso, são potenciais elementos para (re)construção dos percursos formativos dos(as) professores(as) de Química, através de diferentes fontes de ideias e de teorias sem a necessidade de um rigor estético, bem como, pode ser um elemento exclusivo para enaltecer a qualidade de escrita e os saberes que foram escritos, endereçados a algo ou a alguém.

Assim, discutir e solicitar aos(as) estudantes de Licenciatura em Química, quando em período de ESEQ, Cartas abertas e endereçadas às escolas é um potencial gênero para análise, pois há possibilidade de revisitar situações cotidianas que merecem um olhar à subjetividade da prática docente. Consideramos aqui a observação também como práxis docente do estágio supervisionado, mas registrada em Cartas. A Figura 4, apresenta uma Carta escrita por um aluno do curso de Licenciatura em Química e que aborda diferentes visões da relação professor-aluno, contrapondo-se ao que fora vivenciado na escola. 


\section{Figura 4 - Carta sobre a relação professor-aluno, escrita por $\mathrm{CDMC}^{2}$}

A., 19 de Outubro de 2018 .
A Direção da Escola Estadual de Ensino Fundamental e Médio C. B.
A fim de analisar a relação professor-aluno, observei três aulas de um dos professores, através destas
observações pude chegar a algumas consideraçôes. A primeira delas é sobre a importância da boa relação
entre professores e alunos, pude perceber que os alunos não só respeitam mais possuem sentimento de
amizade pelo professor, sempre o tratando bem, dessa forma, tudo flui mais levemente. A segunda
constatação que pude perceber é que a harmonia ou falta dela em sala pode influenciar e muito o processo
ensino-aprendizagem beneficiando ou atrapalhando. Muitos professores não possuem a compreensão
necessária, talvez por alguma falha em sua formação, sobre a importância dessa relação, resumindo o pape.
do professor ao simples papel de transmitir conhecimentos. Como estudante de licenciatura, enxergo essa
elação como a mais importante dentro da escola, entendo que ser professor não se resume a dar aulas,
dentro de uma escola esse profissional por vezes assume o papel de outros profissionais, costumo dizer que
em sala de aula o professor é advogado, para resolver e mediar possiviveis impasses, médico, para identificar
quando um aluno não estar bem, juiz, para tomar decisões justas, psicólogo, para ter a sensibilidade de
perceber quando um aluno precisa de ajuda, percebendo as mudanças em seu comportamento e ajudá-lo,
nem que seja apenas com um conselho ou abraço amigo. Antes de tudo devemos lembrar que nossos alunos
são seres humanos que necessitam de atenção, cuidado, amor, compreensão e educação de qualidade.
Sem outros assuntos a serem tratados nesse momento e desculpando-me pela possivel exposição de críticas
mais rigidas, porém com intuitos construtivos, agradeço antecipadamente a atenção.
Respeitosamente,
C. D. M. C.

Fonte: Os autores (2020)

As cartas têm a competência de expressar os sentimentos dos(as) estudantes do ESEQ quando estão vivenciando a realidade e o cotidiano escolar. $\mathrm{Na}$ Figura 4 temos narrativas sobre a relação professor-aluno e, caso fosse outro gênero, não teríamos apontamentos tão expressivos do(a) estagiário(a). É importante frisar o olhar atento que os(as) licenciandos(as) têm para os(as) alunos(as) do Ensino Médio. Tal ação é necessária para que tenhamos docentes que pensem-nos(nas) como seres humanos e que não estão na escola apenas para receber informações traduzidas (ou não) pelos(as) professores(as) de Química.

A Figura 5 apresenta outra Carta que expressa os olhares do(a) estagiário(a) e suas impressões da prática pedagógica do(a) Professor(a) Supervisor(a) do ESEQ. Esta Carta também foi endereçada à direção da escola-campo.

2 Considerando que a carta tem a função de remeter a alguém assinada por uma outra pessoal, achamos conveniente deixarmos as iniciais $\mathrm{da}(\mathrm{o})$ estudante que elaborou. 


\section{Figura 5 - Carta sobre a impressão da prática pedagógica do Professor Supervisor, escrita por AFS}

Carta á direção - VI
Prática pedagógica
Senhor Diretor (a)
Nas observações em relação a prática pedagógica do professor de Quimica da turma
observada, em suas aulas, pude ver que o método tradicional é bastante presente nas aulas.
As aulas são baseadas na apresentação do conteúdo copiado no quadro e depois explicado
para os alunos. O professor durante as explicações usa exemplos não muito comuns para
os alunos, mas usa também do dia a dia, descrevendo oralmente e escrevendo em texto e
em desenhos no quadro. Nas aulas o professor sempre permite que os alunos façam
perguntas, e sempre que o aluno pede para explicar novamente, pois não entendeu, o
docente explica novamente. Na aula normalmente não é utilizado o livro didático, pois,
como nấo tem para todos os alunos, o professor opta por escrever o conteúdo no quadro,
o que causa desinteresse dos alunos pela aula por terem que copiar o que acaba também
tomando um bom tempo da aula. Nas aulas observadas não foi feito o uso de
experimentação ou de recursos audiovisuais, apenas foi observado que no terceiro
bimestre, foi feita uma roda de conversa onde foi discutido o conteúdo de uma forma
diferente valorizando a atuação dos alunos na exposição de suas ideias e concepções em
relação ou estudado. O docente em suas aulas também procura incentivar a atuação dos
alunos nas aulas, oferecendo um ponto ou até dois, para que responder questionamentos
feitos durante as discussões dos conteúdos. Acredito que o professor deveria propor mais
atividades como a roda de discussão, entre outras atividades que promovam a reflexão, e
que fujam desse modelo tradicional, pois, como diz "Aulas que se revestem apenas de
reprodução de discursos áridos, de manipulação de textos prontos, de ausência de diálogo
criativo e de reflexão em processo deixam de ser práticas pedagógicas, perdem o sentido
e a razão de ser para os alunos", sendo assim necessário que se dê atenção as opiniões e
necessidades dos alunos, para se formular metodologias que atendam as necessidades dos
alunos e promova uma melhor aprendizagem.
Atenciosamente:
A. F. S.

Fonte: Os autores (2020)

Como observado na Figura 5, o(a) estudante remete sua Carta à direção da escola, como forma de apresentar suas impressões sobre as ações pedagógicas do(a) professor(a) nas aulas de Química. O(A) licenciando(a) faz uma observação importante ao estabelecer a prática utilizada pelo docente como uma abordagem tradicional de ensino. Entretanto, a Carta escrita pelo estagiário ressalta a preocupação do professor em esclarecer as dúvidas dos alunos, procurando estabelecer relações entre o objeto da aprendizagem e os conhecimentos de senso comum.

O licenciando também se preocupou em registrar as dificuldades enfrentadas pelo professor ao registrar que o livro didático, adotado pela escola, não existe em número suficiente para todos os alunos, acarretando mais uma demanda ao docente que precisa transcrever todo o conteúdo da aula para o quadro, gerando mais um obstáculo ao desenvolvimento da aula em tempo hábil. 
Também ressaltou em suas observações a ausência de utilização de recursos audiovisuais, procedimentos experimentais e poucos momentos de diálogos realizados através de rodas de conversa, fato que deveria ser mais explorado durante as aulas.

As relações dialógicas existentes nas aulas de Química certamente têm muita importância, sobretudo no que diz respeito à aprendizagem de conceitos e teorias. Entretanto, como trazem os registros da Carta de A.F.S., é possível utilizar diferentes estratégias didáticas para que os(as) estudantes se apropriem das informações necessárias para a aprendizagem, rompendo com o tradicionalismo e vislumbrando o desenvolvimento de habilidades e competências em discentes inseridos na sociedade do século XXI. Esses indivíduos procuram significações para as informações que recebem ao longo da vida. Por isso, A.F.S. propõe em sua carta que $\mathrm{o}(\mathrm{a})$ docente mude a forma como realiza sua práxis.

Quanto ao gênero utilizado, podemos salientar que na Carta há a apresentação de fatos e enunciados importantes para que a escola possa promover discussões a partir dos contextos observados pelos(as) estagiários(as), possibilitando assim, melhorias no que diz respeito aos processos de ensino e de aprendizagem.

Concluímos, então, que as Cartas são gêneros textuais discursivos que também podem ser utilizados como estratégias de registros no ESEQ, pois nos trazem informações numa linguagem simples e de fácil compreensão, sem o rigor preestabelecido no gênero Relatório. Deste modo, afirmamos que as cartas foram importantes instrumentos no processo de registro do/no ESEQ, pois permitiram romper a barreira imaginária que há em "colocar as ideias no papel”. Esta forma de registro da prática enaltece o pensamento espontâneo, a subjetividade e as concepções da profissão docente, através dos olhares atentos dos(as) estudantes.

Ao falarmos e argumentarmos sobre as formas de registro referentes ao Memorial Formativo, ao Diário de Campo e às Cartas, não queremos dizer que em outros gêneros não possa ocorrer o mesmo, mas aqui revelamos diferentes aspectos do uso desses instrumentos no ESEQ como estratégias de registro das práticas. Essas práticas de registro são significantes para relatar o vivido e o percebido no cotidiano escolar pelo futuro professor(a) de Química. Eles demandam atenção e reflexão no uso das palavras, pois há um endereçamento de algo a alguém, há um compromisso de informar os acontecimentos observados durante o ESEQ. 
Esses dispositivos de cunho pedagógico estão relacionados à singularidade do indivíduo que o escreve, com sua história de vida e com suas memórias. pois, em concordância com o que diz Comte-Sponville (1997, p. 43), “[...] nossas cartas se parecem conosco, desde que o queiramos um pouco, e mesmo, às vezes, quando não o queremos".

\section{CONSIDERAÇÕES SEM SER FINAIS}

[...] não há nada de condenável em procurar sobreviver da melhor maneira possível [...]" (MEIRIEU, 1949, p. 12).

A afirmação de Meirieu, com a qual introduzimos estas considerações sem ser finais, é plausível quando temos apresentado documentos pedagógicos que foram e ainda serão utilizados como gêneros textuais e discursivos nos Estágios Supervisionados no Ensino de Química. Escrever não é fácil, sobretudo quando há uma exigência nas universidades de um rigor científico que, muitas vezes, os estudantes têm dificuldades em se adaptar, ficando muitas vezes a cargo de algumas disciplinas do curso, sobretudo na Licenciatura em Química, dos estágios supervisionados - como no curso em questão.

O objetivo de discutir sobre o Memorial Formativo, o Diário de Campo e as Cartas como documentos pedagógicos para a escrita no ESEQ teve por fim apresentar algumas percepções dos(as) licenciados(as) sobre o registro das práticas, vivenciadas durante o estágio. Os documentos pedagógicos são as representações das memórias e das reflexões de cada estudante durante a realização do ESEQ. Assim, qualquer registro aqui apresentado não são denúncias, mas sim, aproximações da realidade escolar e proposições de ações e estratégias diferentes das já realizadas.

Não queremos marginalizar o relatório técnico-científico, mas apresentar propostas que possibilitem outras formas de registros da prática docente, seja em estágios no Ensino de Química ou em outras áreas de conhecimento, contanto que ajudem aos alunos a escreverem e a refletirem sobre sua formação profissional. Também é premente no processo reflexivo, trazido por essas novas formas de registro, o sentimento de partícipes da própria formação, ao mesmo tempo em que ajudam a formar o outro, numa espécie de círculo formativo entre os(as) estudantes.

Defendemos os documentos pedagógicos Memorial Formativo, Diário de Campo e Carta, - além de outros gêneros que ficarão para futuras pesquisas como modelos formativos a serem incorporados aos cursos de formação docente, seja inicial ou continuada. Percebemos, a partir dos dados, que o Memorial Formativo foi essencial para os(as) estudantes, pois, ao escreverem sobre suas 
trajetórias pessoais, se depararam com diferentes modos de construir um olhar sobre o mundo e, até mesmo, sobre a docência. Tratou-se de um exercício de reflexão identitária, que entrelaça família, amigos, instituições onde estudaram, professores que marcaram suas vidas e até algumas experiências universitárias.

Quanto ao Diário de Campo, as escritas revelaram uma aproximação dos sujeitos à ação pedagógica ocorrida nas escolas, sobretudo, nas aulas de Química. Percebemos, que as observações de cada um podem contribuir para a prática docente quando forem atuar como professores(as) de Química. Assim, os registros da prática nos Diários de Campo possibilitaram, conforme as ideias de Zabalza (2004), acessar o mundo pessoal e escolar, vislumbrar o desenvolvimento profissional, enquanto futuros(as) professores(as) de Química e, também, explicitar e avaliar os dilemas que foram encontrados durante o ESEQ. Tais registros poderão colaborar com as ações destes docentes em um futuro próximo em suas profissões.

Já nas Cartas, identificamos que os saberes da experiência estavam relacionados à prática dos professores em formação e que elas se constituíram como elemento fundamental para a afirmação de reflexões das vivências e experiências do ESEQ, sobretudo com propostas diversificadas e com linguagem acessível. Diante desse cenário, esperamos que o curso de Licenciatura em Química ofereça condições para que o professor em exercício relacione seus saberes com a teoria, visando ressignificar a prática, não somente nos ESEQ, mas também nas diversas outras disciplinas formativas do(a) professor(a) de Química. Assim, poderão perceber tais facetas como indissociáveis.

Dessa forma, os gêneros textuais aqui apresentados, analisados e discutidos, não visam substituir outras formas de escrita, apenas são formas de registro da prática que podem favorecer o processo de reflexão da práxis docente, num sentido de aprimorar a autoformação, marcada pela particularidade das próprias escritas e dos diferentes documentos pedagógicos. Assim, fica a critério dos docentes de ESEQ ou de outras áreas de conhecimento sua utilização ou não, pois escrever é, então, um ato político e de liberdade. É a possibilidade de refletir sobre si, sobre a formação, sobre ser professor e sobre as especificidades do Ensino de Química.

É substancial escrever sobre as experiências vividas nas práticas profissionais, pois as narrativas nos auxiliam na interrogação dos saberes e dos fazeres, tornando-nos docentes críticos e reflexivos. Assim, compreendemos a importância de dar voz, sentidos e significados ao que cada registro quer nos (in) formar, a fim de identificarmos a verdadeira mudança da realidade acontecida e oportunizada pelo ESEQ. 


\section{REFERÊNCIAS}

BARDIN, Laurence. Análise de conteúdo. São Paulo: Edições 70 Brasil, 2011.

BRASIL. Parecer CNE/CES n. 1303/2001, de 06 de novembro de 2011. Define as Diretrizes Curriculares Nacionais para os Cursos de Química. Diário Oficial da União, Brasília, 7 Dez. 2001. Disponível em: http://portal.mec.gov.br/cne/ arquivos/pdf/CES1303.pdf. Acessado em: 04 abr. 2019.

BRASIL. Resolução CNE/CEB n. 4/2010, de 13 de julho de 2010. Define as Diretrizes Curriculares Nacionais Gerais para a Educação Básica. Diário Oficial da União, Brasília, 14 jul. 2010. Disponível em: http://portal.mec.gov.br/ dmdocuments/rceb004_10.pdf. Acessado em: 04 abr. 2020.

BRASIL. Resolução CNE/CP n. 2/2015, de 1 de julho de 2015. Define as Diretrizes Curriculares Nacionais para a formação inicial em nível superior (cursos de licenciatura, cursos de formação pedagógica para graduados e cursos de segunda licenciatura) e para a formação continuada. Diário Oficial da União, Brasília, 02 jul. 2015. Disponível em: http://portal.mec.gov.br/dmdocuments/ rceb004_10.pdf. Acessado em: 15 abr. 2019.

CABRAL, Wallace Alves; FLÔR, Cristhiane Carneiro Cunha. (Re)pensando as práticas de escrita na disciplina de Estágio Supervisionado em Química: com a palavra, os estagiários. Ensaio. Belo Horizonte, n. 3, v. 18, p.51-64, 2016.

CAMARA BASTOS, Maria Helena. Reseña de "Carta a um jovem professor". Educação, vol. XXIX, núm. 3, setembro-dezembro, 2006, pp. 654-648.

COMTE-SPONVILLE, André. A correspondência. In: Bom dia angústia. São Paulo: Martins Fontes, 1997.

GIL, Antônio Carlos, 1946. Como elaborar projetos de pesquisa.4. ed. - São Paulo: Atlas, 2002.

GLEISER, Marcelo. Cartas a um jovem cientista. 3.ed., Rio de Janeiro: Elsevier Editora, 2007.

LÜDKE, Menga; ANDRÉ, Marli Eliza Dalmazo Afonso de. A. Pesquisa em Educação: abordagens qualitativas. São Paulo: EPU, 1986. 
MEIRIEU, Philippe. Carta a um jovem professor. Porto Alegre: Artmed, 2006. $96 \mathrm{p}$.

MOURA, Berno Arsioli. Concepções inadequadas de ciência e fazer científico: análise de um exemplo na literatura. Prometeica, año IV, n. 19, 2014.

PASSEGGI, Maria da Conceição. Memoriais: injunção institucional e sedução autobiográfica. In: PASSEGGI, Maria da Conceição; SOUZA, Elizeu Clementino de. (Org.) (Auto)biografia: formação, territórios e saberes. Natal: EDUFRN, 2008a, p. 103-131.

PASSEGGI, Maria da Conceição. Memoriais auto-biográficos: a arte de tecer uma figura pública de si. In: PASSEGGI, M. Conceição; BARBOSA, Tatyana Mabel Nobre (Org.). Memórias, memoriais: pesquisa e formação docente. Natal: EDUFRN; São Paulo: PAULUS, 2008b. (Coleção Pesquisa (Auto)Biográfica e Educação).

PIMENTA, Selma Garrido; LIMA, Maria Socorro. Estágio e docência. Colabs.: Erika Barroso Dayanny e Elisângela André da Silva. 8. ed., atual. e ampl., São Paulo: Cortez, 2017.

QUEIROZ, Salete Linhares. A linguagem escrita nos cursos de graduação em Química. Química Nova. São Paulo. v.24, n.1, p.143-146. 2001.

SEVERINO, Antônio Joaquim. Metodologia do trabalho científico. 23. ed. São Paulo: Cortez, 2007.

SILVA, Fábio Adriano Santos da; FIREMAN, Elton Casado. Desenvolvimento das aulas experimentais de química pelo tutor: um estudo no Pólo Maceió do curso EaD da UFRN. Scientia Plena, v. 9, n. 12, 2013b. Disponível em: < https:// www.scientiaplena.org.br/sp/article/view/1147/919>. Acesso em: 04 ago. 2019.

SOUZA, Elizeu Clementino de. O conhecimento de si: estágio e narrativas de formação de professores. Rio de Janeiro: DP\&A; Salvador: UNEB, 2006.

SOUZA, Leandro Nunes. O Estágio Supervisionado no curso de Licenciatura em Ciências Biológicas da Universidade Federal de Goiás - Campus - Goiânia. Dissertação (Mestrado). Universidade Federal de Goiás, Planetário, 2013. 
SCHÖN, D.A. Educando o Profissional Reflexivo: um novo design para o ensino e a aprendizagem. Trad.Roberto Cataldo Costa. Porto Alegre: Artmed, 2000, 256p.

TARDIF, Maurice. Saberes docentes e formação profissional. 15. ed., Petrópolis: Vozes, 2014.

TRIVIÑOS, Augusto Nibaldo Silva. Introdução à pesquisa em ciências sociais: a pesquisa qualitativa em educação. São Paulo: Atlas, 1987.

VIANNA, Ilca Oliveira de Almeida. A formação de docentes no Brasil: história, desafios atuais e futuros. In: RIVERO, Cléia Maria da Luz; GALLO, Silvio. (orgs.). A formação de professores na sociedade do conhecimento. Bauru: Edusc, 2004, p. 21-54.

ZABALZA, Miguel. A. Diários de aula: um instrumento de pesquisa e desenvolvimento profissional. Trad. Ernani Rosa. Porto Alegre: Artmed, 2004.

\section{Franklin Kaic Dutra-Pereira}

Licenciado em Química (CES/UFCG) e um dos doutores mais jovens do país em Ensino de Ciências e Matemática (PPGECM/UFRN). Professor do CFP/UFRB. Líder do Grupo Pesquisa Ensino e Extensão em Educação Química (PEQUI). Integrante do Grupo de Estudos e Pesquisa em Políticas Curriculares (GEPPC). Dialoga sobre Arte, Educação e Química na Formação de Professores(as) de Ciências [repudia o neoliberalismo e o neofascismo que alastra pelo Brasil] e, destitui o mito com conhecimento científico. E-mail: franklinkaic@ufrb.edu.br

\section{Michele Marcelo Silva Bortolai}

Licenciada e Bacharel em Química (MACK/SP) e Pedagogia (UNG/SP). Especialista em Química (FOC/SP), Mestre e Doutora em Ensino de Ciências (PIEC/USP). Professora Adjunta em Ensino de Química do CFP/UFRB. Integrante dos Grupos de Pesquisa PEQUI (UFRB) e LiEQui (USP). Estudos voltados à formação de professores, aos processos de ensino e aprendizagem em Química e Ciências e à Teoria da Representações Sociais. E-mail:michelemsb@ ufrb.edu.br 


\section{Rafaela dos Santos Lima}

Curiosa que sou, me licenciei em Química (UFRB), me especializei em Docência do Ensino Superior (UCAM). Precisando me (re)iventar e (re)significar me constituo mestra em Educação Científica e Formação de Professores (UESB/ PPGECFP). Hoje, velejo mares (des)conhecidos para me doutorar em Ensino, História e Filosofia das Ciências (UFBA/PPGEFHC). Pesquisar, estudar, formar... é também semear, por isso participo do Grupo de Pesquisa Ensino Extensão em Educação Química (PEQUI) da UFRB. Em todas essas idas e vindas pesquiso, discuto, reflito sobre Currículo e Formação de Professores na interface gênero, diversidade e relações étnico-raciais. Email: limasrafaa@gmail. com 